\title{
Evaluation of Wear Measurement With Radioactive Isotopes for DLC Coatings Affected by Abrasive Particles
}

\author{
Manuel Zellhofer ( $\square$ manuel.zellhofer@ac2t.at ) \\ AC2T research GmbH https://orcid.org/0000-0002-8003-9719 \\ Martin Jech \\ AC2T research $\mathrm{GmbH}$
}

\section{Ewald Badisch}

AC2T research $\mathrm{GmbH}$

\section{Ferenc Ditrói}

Atomi

\section{Andreas Kuebler}

Robert Bosch GmbH Stuttgart

\section{Paul Heinz Mayrhofer}

Vienna Technical University: Technische Universitat Wien

\section{Research Article}

Keywords: Diamond-Like Carbon (DLC) , Radio-Isotope Concentration (RIC) method, Wear progression monitoring , Irradiation influence, Abrasive particles impact

Posted Date: January 18th, 2022

DOI: https://doi.org/10.21203/rs.3.rs-1257374/v1

License: (9) This work is licensed under a Creative Commons Attribution 4.0 International License. Read Full License

Version of Record: A version of this preprint was published at Tribology Letters on April 24th, 2022. See the published version at https://doi.org/10.1007/s11249-022-01587-2. 


\title{
Evaluation of wear measurement with radioactive isotopes for DLC coatings affected by abrasive particles
}

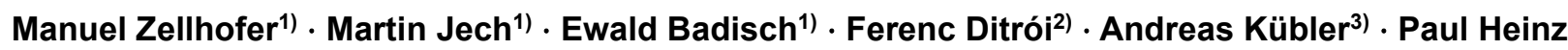 \\ Mayrhofer ${ }^{4}$
}

Received:

(c) Springer

\begin{abstract}
Diamon-like carbon (DLC) coatings protect engine parts from wear and provide low-friction. Unfortunately, the nature of DLC coatings does not allow progressing wear measurement using conventional methods. Therefore, we applied a radioactive isotope-based wear measurement method (RIC method). A tribometer with oscillating contact and one with sliding contact were used to provide different loading conditions. The RIC method was evaluated for DLC coatings, and the DLC wear was investigated regarding the presence of abrasive particles. The results indicate that an increase in abrasive particle concentration leads to an increase of DLC wear rate and a decrease in usage-time until wear-off.
\end{abstract}

Keywords Diamond-Like Carbon (DLC) · Radio-Isotope Concentration (RIC) method - Wear progression monitoring $\cdot$ Irradiation influence $\cdot$ Abrasive particles impact

\section{Introduction}

Diamond-like carbon (DLC) coatings are applied to engineering components to minimize surface wear and provide low-friction [1], [2]. In the valve train of automotive applications and at tribometer level, a friction reduction of $20 \%$ to $90 \%$ can be observed compared to wear-resistant coatings, such as TiN [3]-[6]. Combined with superlubricity effects, the efficiency of the tribo-systems can further be improved, thus energy can be saved (which is essential not just for combustion engines but also the evolving E-mobility) [7]. For such applications, the thickness of DLC coatings is typically in the range of 1 to $4 \mu \mathrm{m}$ [8]. Regardless of the superb

\section{Manuel Zellhofer}

manuel.zellhofer@ac2t.at

${ }^{1}$ AC2T research $\mathrm{GmbH}$, Wiener Neustadt, Austria

${ }^{2}$ Institute of Nuclear Research of the Hungarian Academy of Sciences, Debrecen, Hungary

${ }^{3}$ Robert Bosch GmbH, Feuerbach, Germany

${ }^{4}$ Institute of Materials Science and Technology, Vienna University of Technology, Austria properties, unintended failure of DLC coatings can be observed. Thus, a further optimization of the DLC coatings and the knowledge about critical loading conditions is the challenge for automotive [5], medical [9], and aerospace [10] applications.

"Today DLC films have been indispensable for diesel injection systems (...)" [10]. Thus, further friction and wear experiments in the field of automotive components were carried out for clarifying the effects on DLC wear [8], [11]-[13]. Especially in the automotive industry, failure due to delamination is an undesirable phenomenon, and especially abrasive wear particles lead to delamination processes [14]. Nevertheless, it is not clear yet, if the presence of abrasive particles causes a spontaneous coating delamination or if the DLC coating continuously wears-off.

A continuous measurement method for wear monitoring is required for this investigation. Radioactive isotopes proved to be efficient tracers that allow for high-sensitive wear measurement [15], but also continuous monitoring of wear progress, e.g., applied on metallic engine components [16], [17]. For using such a method, one or both interacting bodies need to be irradiated by, e.g., thin layer activation (TLA) [15], [17]-[19]. The irradiation resulted in an activated state in which the near-surface zone, and thus the generated wear particles, contain radioactive isotopes. 
The wear of different materials can be measured parallel and continuously by using different isotopes [15]. Previous studies have shown that such a tracer method is suitable for wear studies on different materials or under various loading conditions [16], [20], [21]. Berlet et al. [22] and Faller et al. [23] used radio nuclide tracers for DLC wear studies and found loading condition dependent wear rates.

However, any kind of irradiation is energy input that can have side effects on the material, e.g. induced temperature and structural changes can influence the tribological performance. Tani et al. [24] reported a lower coefficient of friction (COF) due to laser irradiation (heating). Fan et al. [10] investigated the influence of space irradiation (atomic oxygen, ultraviolet, protons, and electrons). A change in COF and wear behavior was observed with an irradiation from $2.5 \times 10^{14}$ to $6.5 \times 10^{15} \mathrm{~cm}^{-2} \mathrm{~s}^{-1}$. Fan et al. [25] showed that Helium $(\mathrm{He})$ ion irradiation leads to an increase in nano-hardness and a decrease in surface roughness. Using RAMAN, they observed a microstructural evolution to a structure containing a large fraction of sp2hybridized structure clusters. The irradiation in these experiments was $10^{15}$ to $10^{17} \mathrm{~cm}^{-2}$. Vankar et al. [26] listed $\mathrm{He}$ irradiation $\left(10^{12}\right.$ to $\left.10^{16} \mathrm{~cm}^{-2}\right)$ influence on DLC. Wu et al. [27] and Zhang et al. [28] found tribological improvements after irradiation with $\mathrm{He}^{+}\left(10^{15}\right.$ to $\left.10^{17} \mathrm{~cm}^{-2}\right)$, atomic oxygen or ultraviolet radiation. These irradiations are in a comparable range to those required for the activation of DLC. However, the mentioned references showed that less particles per area or per unit time is more favorable in terms of less influence on the DLC. Therefore, low activations are preferable and thus are used in this study to investigate DLC wear processes.

The aim of this study is:

- to investigate the influence of the irradiation method on the structure by for example sp2 (graphite) and sp3 (diamond) hybridization content [29] and on the tribological behaviour of the DLC,

- to evaluate the radioactive tracer methods applied on DLC, and

- to investigate the wear progress or even wear rates under presence of abrasive particles.

Two tribological systems were selected for this purpose. Firstly, a ball against plate experiment with oscillating motion was set up to investigate the influence of the irradiation on the tribological performance at critical loading conditions. Secondly, a cylinder against plate experiments with unidirectional sliding conditions was chosen to study the wear progress due to the impact of added abrasive particles at subcritical loading conditions.

\section{Methods}

\subsection{Test setup for wear measurement}

The wear measurement is based on the radioactive isotope concentration (RIC) method [15]-[18]. Within this study, a $1 \mu \mathrm{m}$ mash-size filter was placed in the gamma ray detector within the lubricant circuit for gathering most of the wear particles in the detector measurement zone, see Fig. 1b. Fresh diesel was used in each experiment, circulated with a tube squeeze pump at about $\sim 30 \mathrm{ml} / \mathrm{min}$. All experiments were carried out with diesel (GDK 570) at room temperature.

\subsection{Preparation/Irradiation of samples}

The DLC coated samples (plates and liners) were provided by Robert Bosch $\mathrm{GmbH}$ and had the same DLC coating with roughly $2.3 \mu \mathrm{m}$ thickness, 170 GPa Young's modulus, and 20 GPa Hardness, as obtained from our measurements, Tab. 2. The substrate was steel, and a chromium layer acted as an intermediate layer between the DLC and the steel substrate. DLC activation is achieved by irradiation of carbon with helium $\left({ }^{3} \mathrm{He}\right)$. During this irradiation, a nuclear reaction forms ${ }^{7} \mathrm{Be}$ from the stable carbon ${ }^{12} \mathrm{C}$ [30]. Mentioning briefly, that undoped DLC was used within this study and consequently no other isotopes can be produced from doping elements, e.g., Ti or W.

${ }^{7} \mathrm{Be}$ has a gamma energy line of $478 \mathrm{keV}$ and a halflife of 53 days. Because irradiation depth was $\sim 10 \mu \mathrm{m}$, the substrate steel was co-activated during the irradiation process by generating Co57 isotopes [17]. This allows to determine the point at which the DLC coating is rubbed/worn through when Co57 is detected during the tribological experiment.

The irradiation of the samples was carried out with low beam parameters to achieve hardly any material changes in the irradiated area. Thereby we achieved that the irradiated samples provided a good sensitivity regarding the wear measurement whereby the sample contain a total activation below the free handling limit [31].

The counter acting bodies have not been irradiated and thus were not accessible for tracer wear measurement. Nevertheless, material transfer from the sample onto the counter acting bodies is detectable after the experiment. 


\subsection{Selection of tribological model systems}

To evaluate the effect of irradiation, tribometer experiments were carried out with DLC coated plates with and without irradiation using a standard tribometer (Universal Mechanical Tester - UMT, Bruker) with oscillating movement. In the following, these tests are labelled "UMT".

Three tests were performed on irradiated DLC plates and three tests on original (without irradiation) DLC plates. In these experiments, the tribological behaviour without failure or severe damage of the DLC coating was of interest. These loading parameters were evaluated previously to obtain stable and non-failure conditions.

A $100 \mathrm{Cr} 6$ ball with $10 \mathrm{~mm}$ in diameter was used as the counter acting body, Fig. 1a. The load was chosen to provide an initial Hertzian contact pressure of $2,750 \mathrm{MPa}$. The oscillating frequency was set to $25 \mathrm{~Hz}$ with a stroke of $4 \mathrm{~mm}$ and the test duration to $30 \mathrm{~min}$, respectively.

The COF of these experiments was evaluated from the peak values (top $10 \%$ of the data) over the stroke.

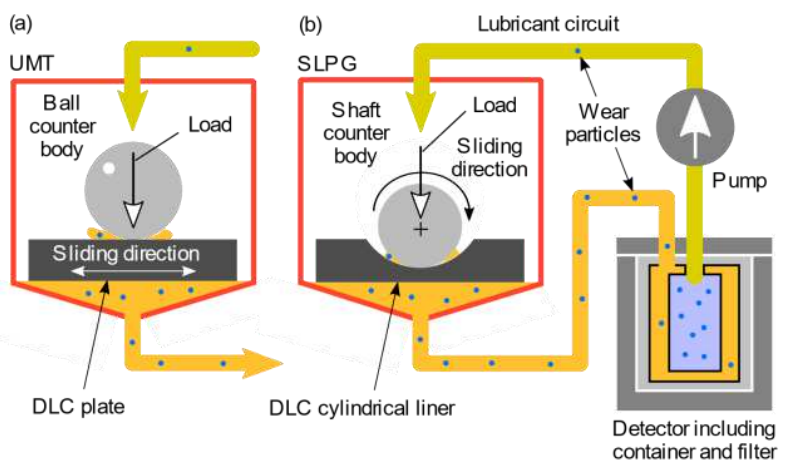

Fig. 1 Schematic illustration of the RIC-tribometer-circuit and DLC samples sliding and loaded against a ball during the UMT test (a) and against a shaft during the SLPG test (b). The pump transports the lubricant including the isotopes within the wear particles through the circuit to the detector. A $1 \mu \mathrm{m}$ filter was placed in the detector.

To study the wear progress due to presence of abrasive particles, a steel shaft was unidirectional slid against a DLC-coated cylindrical liner using a journal bearing tribometer (Sinterlagerprüfgerät SLPG, SKF - OENORM M 8124:2009-03-01), Fig. 1b. These tests were labelled in the following "SLPG". The DLC coated cylindrical liner had a diameter of $12 \mathrm{~mm}$ and a length of $20 \mathrm{~mm}$. The shaft counter-body was made of X90CrMoV18 with a diameter of $8 \mathrm{~mm}$. For these experiments a Hertzian initial contact pressure of $275 \mathrm{MPa}$ was selected, that is significantly below pressures for which failure of DLC can be expected.

Velocity ramps from 0 to $0.2 \mathrm{~m} / \mathrm{s}$ and back to $0 \mathrm{~m} / \mathrm{s}$ (one ramp 10 seconds long) were used to simulate start-up movements that lead to a change from boundary to mixed lubrication conditions. Additionally, constant velocity tests at $0.2 \mathrm{~m} / \mathrm{s}$ were applied, Tab. 1. These conditions are deducted from the related engine application and hardly any wear of the DLC coating is expected for such conditions. However, the DLC coatings in the application sometimes wear-off and delaminate under similar loading conditions. For investigating possible reasons of critical loading conditions, the SLPG tribometer experiments were enhanced by abrasive particles. These abrasives were collected from previous experiments on engine test benches and tribometers with the related tribo-system, where failure of the DLC was observed.

These abrasives were filtered by $1 \mu \mathrm{m}$ mesh size before adding to the experiments and a filter of $1 \mu \mathrm{m}$ mesh size is applied in the lubricant circuit as well. Thus, the size of the abrasive particles is below 1 $\mu \mathrm{m}$. The experiments are varied by different concentrations of these abrasive particles.

Tab. 1 SLPG-DLC liner experiments with different abrasive particle concentrations. The particle concentration of experiments $A$ to $C$ were unaltered, where else for experiment $D$ abrasive particles were added twice during the experiment.

\begin{tabular}{ccc}
\hline Experiment & $\begin{array}{c}\text { Relative } \\
\text { velocity }\end{array}$ & $\begin{array}{c}\text { Abrasive particle } \\
\text { concentration } \\
<1 \mu \mathrm{m}, \\
10^{6} \text { particles } / \mathrm{ml}\end{array}$ \\
\hline SLPG-A & Ramps & High \\
SLPG-B & Ramps & Medium \\
SLPG-C & Constant & Low \\
SLPG-D & Constant & Variation \\
\hline
\end{tabular}

Concerning the uncertainties of sub-micrometer particle measurement in lubricants (regarding sample taking, dilution, particle size distribution, etc.) a statistical approach has to be chosen to evaluate the particle concentration for each experimental setup and loading condition. Therefore, three lubricant samples (each $\sim 0.5 \mathrm{ml}$ ) were taken at different time steps of the experiment to evaluate the average particle concentration. As the particle concentration may vary over time due to wear, filter efficiency, and particle deposition in the circuit, the experiments are described by the average particle concentration for each loading condition.

In total four experiments with abrasive particles were carried out, Tab. 1. High, medium, and low particle concentrations in the range of $10^{6}$ particles per milliliter were selected for tests SLPG-A, B, and $C$, respectively. For experiment SLPG-D the particle concentration was varied by adding abrasive 
particles into the circuit during the experiment.

The measured particle concentration is consequently the sum of the initial abrasive particles and the generated DLC wear particles and is named abrasive particle concentration in the following. The abrasive particle concentration was evaluated with the particle measurement device (particle measurement, AC2T) [32].

\subsection{Analysis of DLC coating}

Topographical measurements of the irradiated surface and the original surface were compared based on the roughness and the worn volume. These measurements were carried out by a chromatic confocal profiler (Jr25, Nanovea), which provides a lateral resolution of $1.3 \mu \mathrm{m}$ and vertical resolution of $5.7 \mathrm{~nm}$. In the post evaluation (Leica Map, Leica Microsystems) of the measured topography, the geometrical shape of the sample was removed to evaluate the wear volume of the wear track.

Nanoindentation was performed with a load of $10 \mathrm{mN}$, resulting in penetration depths of 120 to $150 \mathrm{~nm}$, as reported by Zhang et al. for similar analyses [33]. Tischler et al. showed that the substrate does not have an influence at this load compared to higher loads [34]. For statistics, we selected three independent positions for nanoindentations in the irradiated and in the original surface, respectively.

To investigate the DLC morphology (and sp2content) after the tribological tests, three lamellae were prepared for transmission electron microscopy (TEM, FEI TECNAI F20) analysis using focused ion beam (FIB). One lamella sample was taken from the irradiated-unworn area, one in the original-unworn area, and one in irradiated-worn area. An electron energy loss spectroscopy (EELS) was carried out via line scans with a step size of $2 \mathrm{~nm}$, starting at the interlayer and ending at the DLC coating surface. The sp2 and sp3-peaks were considered to evaluate the sp2-content using formula from Chu et al. [35] and a graphite reference spectrum from an EELS database [36]. A DLC reference spectrum from that database was used to validate our calculation process.

\section{Results}

\subsection{Comparison of irradiated and original DLC plate samples in reciprocating tests (UMT)}

The light microscope image shows no significant change in color at the transfer zone between the $2 \mathrm{~mm}$ wide irradiated surface and original surface, Fig. 2a. High-definition topographical images of the irradiated surface Fig. $2 \mathrm{~b}$ and of the original surface Fig. 2c indicate a similar and comparable visual appearance. Both microscopy images show scratches and pores irregularly distributed over the entire surface. For these regions - irradiated and original - a roughness value $\mathrm{Ra}$ of $0.18 \pm 0.02 \mu \mathrm{m}$ was evaluated by these topography measurements, indicating that the irradiation does not (significantly) affect the DLC surface appearance.

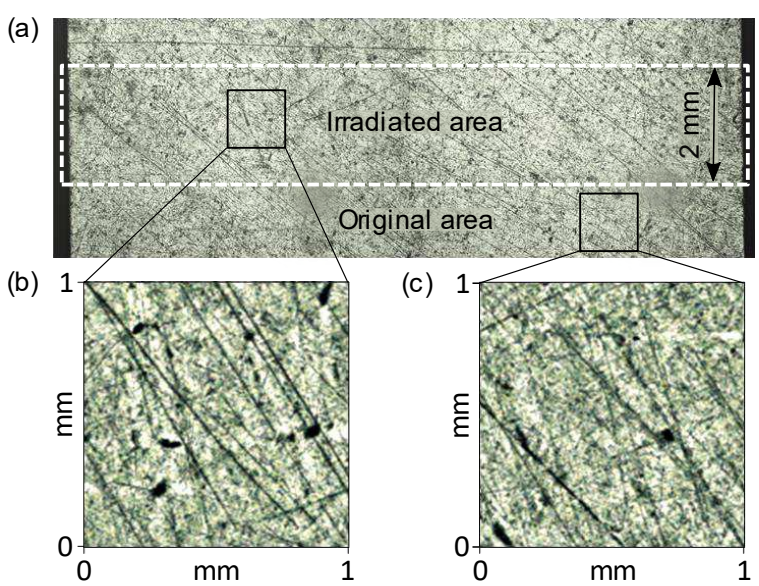

Fig. 2 Light microscopy and topographical images of the irradiated UMT-DLC plate sample: overview of sample surface (a), detail of irradiated surface (b), and detail of original surface (c).

The topographical measurements show no noticeable difference when comparing the UMTDLC wear tracks on the irradiated sample, Fig. 3a, and on the original sample, Fig. 3b. Groves can be seen in both wear tracks along the sliding direction. Furthermore, the evaluations show comparable cross-sections and wear track depths of $\sim 0.5 \mu \mathrm{m}$ in the middle of the wear tracks, Fig. $3 c$ and d. This is affirmed by the averaged wear volume of $4.4 \times 10^{5} \pm 2.4 \times 10^{5} \mu \mathrm{m}^{3}$ of the three tracks of the irradiated DLC compared to the averaged wear volume of $4.5 \times 10^{5} \pm 2.1 \times 10^{5} \mu \mathrm{m}^{3}$ of the three tracks of the original DLC. 

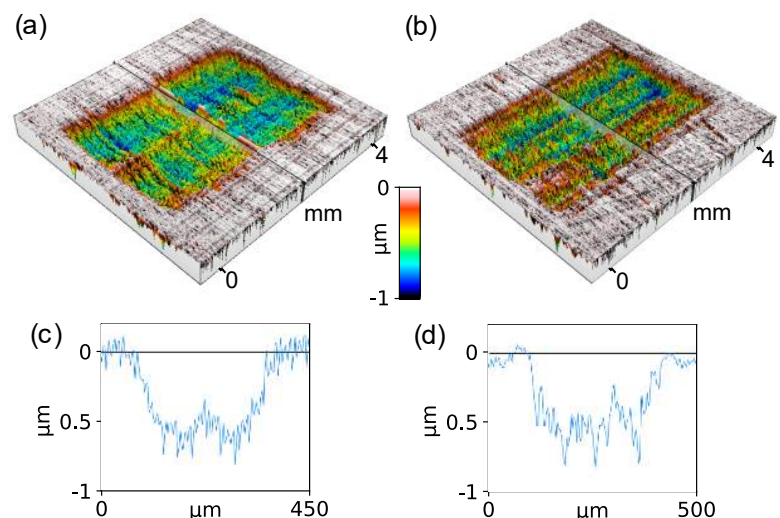

Fig. 3 Wear tracks from an irradiated (a) and original (b) UMT-DLC plate sample and their corresponding cross sections (c) and (d).

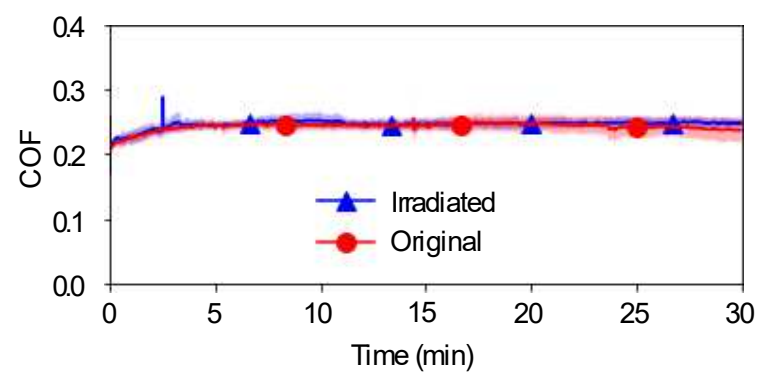

Fig. 4 Averaged COF over time from experiments on the irradiated and on the original UMT-DLC plate samples.

The averaged COF of the experiments with the irradiated and in the original samples show similar trends over time, Fig. 4. Both COF curves start with a running-in behavior up to $\sim 2.5 \mathrm{~min}$ (3,750 cycles). Afterwards, the COF curves reach a steady-state behavior of $0.247 \pm 0.011$ for the irradiated samples and $0.245 \pm 0.010$ in the original samples, showing any difference.

The TEM analyses (including energy dispersive $X$ ray spectroscopy - EDX) show a $\sim 2,300 \mathrm{~nm}$ thick DLC coating on a steel substrate, Fig. 5 . A $\sim 375 \mathrm{~nm}$ chromium and a $\sim 150 \mathrm{~nm}$ chromium carbide layer act as intermediate layers. Comparable sp2-content was evaluated from the irradiated-unworn $(55 \pm 3 \%)$ and original-unworn samples $(55 \pm 2 \%)$. In comparison, a higher proportion of $58 \pm 2 \%$ was found in the irradiated-worn sample near the surface. This may indicate an influence of the wearing process, observable as a shift of the sp3 percentage to $\mathrm{sp} 2$ percentage. All three analyzed TEM samples - irradiated-unworn, original-unworn and irradiated-worn - showed an amorphous structure of the DLC.

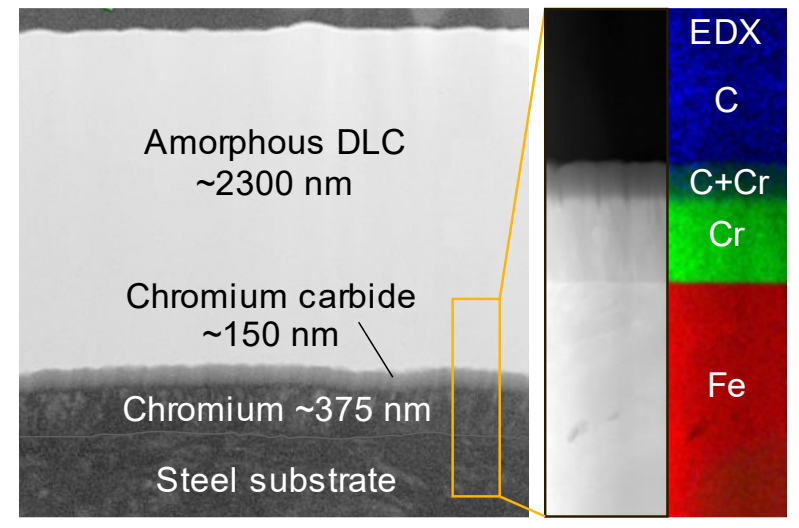

Fig. 5 TEM pictures and EDX analysis of the FIB Lamella from an original UMT-DLC plate sample.

Tab. 2 Summed and averaged results of the analyzed UMT-DLC plates comparing irradiated and original samples.

\begin{tabular}{lcc}
\hline Sample/condition & $\begin{array}{c}\text { Irradiated } \\
\text { unworn }\end{array}$ & $\begin{array}{c}\text { Original } \\
\text { unworn }\end{array}$ \\
\hline Roughness $\mathrm{Ra}, \mu \mathrm{m}$ & $0.18 \pm 0.02$ & $0.18 \pm 0.02$ \\
sp2-content, \% & $55 \pm 2$ & $55 \pm 3$ \\
Hardness, GPa & $20 \pm 3$ & $19 \pm 3$ \\
Young's modulus, & $175 \pm 14$ & $172 \pm 12$ \\
GPa & Irradiated & Original \\
\hline Sample/condition & and worn & and worn \\
\hline DLC wear, $10^{5} \mu \mathrm{m}^{3}$ & $4.4 \pm 2.4$ & $4.5 \pm 2.1$ \\
sp2-content, \% & $58 \pm 2$ & - \\
COF & $0.247 \pm 0.011$ & $0.245 \pm 0.010$ \\
\hline
\end{tabular}

In summary, no significant difference was found comparing irradiated and original samples, as shown by the collected data, including hardness and young's modulus from nanoindentation studies, Tab. 2. Regarding the counter acting bodies (100Cr6 balls), the wear volumes for tests against irradiated and original samples are also similar within their uncertainties, being in average $8.8 \pm 2.6 \times 10^{5} \mu \mathrm{m}^{3}$ for the balls against the irradiated DLC and $7.0 \pm 1.1 \times 10^{5} \mu \mathrm{m}^{3}$ for the balls against original DLC.

\subsection{Wear of DLC with abrasive particles}

In Fig. 6 the SLPG-results for the tests SLPG-A to C are displayed, which had no addition of abrasive particles to the initial concentration (unaltered). The wear of the DLC coating is displayed in Fig. 6a and the wear of the co-activated steel-substrate in Fig. $6 b$.

The results show that DLC wear starts immediately, whereas steel-substrate wear is recognisable with a time delay of $\sim 2.5$ hours. The trend of the DLC wear due to presence of these abrasive particles can be described to be slightly progressive, which leads to 
wear-off the DLC coating after some time. The behavior may be due to continuous damage of the DLC coating or due to the increase of abrasives with progressing wear. Interestingly, no running-in effect is observed the wear data, as normally is occurring for metallic surfaces [16]. The wear mechanism of the DLC coating is-under these loading conditions - consequently different to those wear mechanisms of (elastic) metals.

(a)

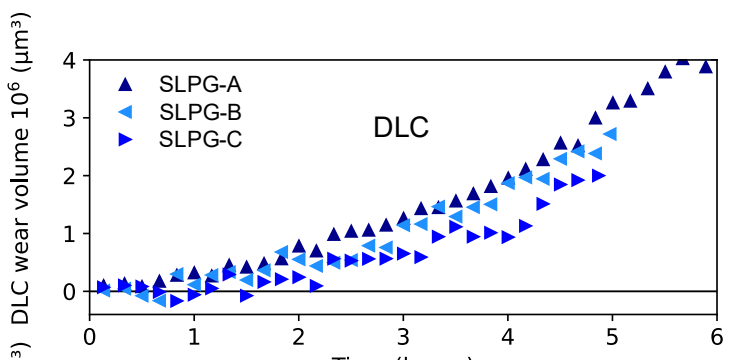

(b)

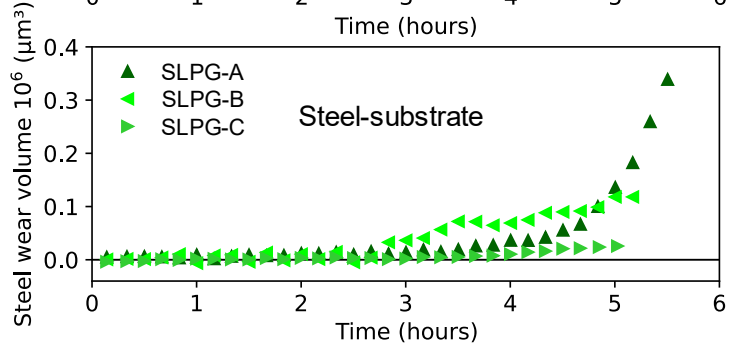

Fig. 6 SLPG-DLC liner wear (experiment SLPG-A to C) starts from the beginning under abrasive particles (a). Compared to DLC wear, steel-substrate wear starts with a time delay (b).

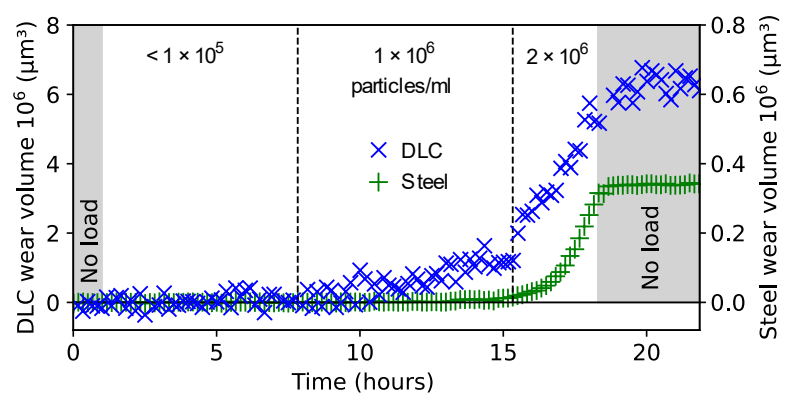

Fig. 7 Continuous wear measurement (SLPG-DLC liner, Experiment SLPG-D) of the DLC coating and steelsubstrate at three different particle concentrations: particles < $1 \times 10^{5}, 1 \times 10^{6}$, and $2 \times 10^{6}$ particles $/ \mathrm{ml}$. Grey-filled areas at start and end sections represent no load and no tribometer operation.

The continuous wear data of experiment SLPG-D shows DLC wear over time at different abrasive particle concentrations, Fig. 7. No DLC wear increase is observed at a concentration of $<1 \times 10^{5}$ particles per milliliter. By increasing the concentration of abrasive particles to $1 \times 10^{6}$ and to $2 \times 10^{6}$ particles per milliliter, the wear increases significantly.

A time-delayed wear from the steel-substrate is evident in experiment SLPG-D, as also experienced in experiments SLPG-A to C. Since the co-activated steel substrate was measured in all SLPG-DLC experiments, this is a clear indication that the DLC coating is rubbed off at certain points of the contact area. The steel wear volume found in experiment SLPG-A to $D$ is in the range of $5 \pm 3 \%$ in relation to the DLC wear volume. For tests $A$ and $D$ also a material transfer from the steel substrate to the counter acting body was measurable, which behaves like the total wear volume of test $A$ to $D$.

\section{Discussion}

\subsection{Impact of irradiation on tribological behavior of DLC coatings}

Comparing the optically measured wear volume of the irradiated and the original UMT-DLC plate samples, the averaged wear volumes are the same within their uncertainties. Unfortunately, the standard deviations of three different wear tracks are rather high, in the range of $\sim 50 \%$ of the value of the wear volume, Tab. 2. These uncertainties contain the influences of the optical measurement method but also the statistical variations of surface features, such as pores and scratches in the tribological contact zone [6]. Similar standard deviations were evaluated for optical post measurements by $\mathrm{Li}$ et al. for comparable wear volumes [37]. The uncertainties due to systematic errors of optical methods [38]-[41] are not regarded within the uncertainty values.

Supplementary to the wear volume, also the evaluated COFs are the same for the irradiated and the original UMT-DLC plates, Fig. 4. Summarising the tribological performance but also the analysed material properties (e.g. hardness, topography, and morphology, see Tab. 2), the influence of the irradiation on the DLC coating can be neglected. This statement has to be seen with respect to the chosen irradiation parameters for the presented study, which led to activations below the free handling limit of each sample.

\subsection{Wear particles}

In the following, we differentiate between the abrasive particles, which are determined with the particle measurement method, and the wear particles from the DLC coatings, which contain radioactive isotopes and are detected by the RIC method.

In the online measurement of the RIC method, the DLC particles are detected, which are in the measuring zone of the detector. This zone contains the $1 \mu \mathrm{m}$ filter as well as a certain volume of the lubricant. The wear particles, which are flowing in 
the rest of the circuit, or which are deposited outside of the detector zone, are not captured during the online measurement. The relation of online captured particles and non-captured particles has to be evaluated by post measurements of the circuit components.

For evaluating all possible deposits of wear particle containing radioactive isotopes, the individual components (e.g. tubes and the sample holder) of the lubricant circuit were examined after each experiment. For this measurement, the individual shielding and the specific geometry factor for each component was considered in the gamma activity analysis.

The measurements of the circuit show that DLC wear particle traps may occur in the holder or in the tubes, as the DLC particles may get stuck due to the squeezing of the pump. Nevertheless, the measurements of the individual components show that the main content of the DLC wear particles is detected in the filter and lubricant.

Based on the post measurements of the individual components, an average DLC wear particle content of $72 \pm 9 \%$ was evaluated for the filter, $15 \pm 13 \%$ for the lubricant, $8 \pm 7 \%$ for the circuit, and $6 \pm 6 \%$ for the counter-body, Tab. 3. The percentage is related to the total wear of each experiment, respectively, and subsequently averaged for the individual experiments.

Through these post measurements, a relation of online measurement and total wear volume can be established for such measurement set-ups and an uncertainty estimated in the range of $\pm 0.6 \times 10^{6} \mu \mathrm{m}^{3}$ for the RIC wear volume. As the total wear volume is achieved, it can be compared with the optically determinable wear volume.

Independently evaluated wear volumes from three topography measurements of each SLPG-DLC sample are averaged and a standard deviation derived in the range of $\pm 0.5 \times 10^{6} \mu \mathrm{m}^{3}$. The uncertainty of optical post measurements for the SLPG samples is higher than for the UMT plates due to the higher total wear volumes of SLPG tests compared to UMT tests and due to the shape of the reference areas. The cylindrical area around the wear scar is taken as the reference area for the SLPG samples in comparison to the flat reference areas of the UMT plates.

The wear volumes derived from the RIC continuous wear measurement, the RIC post measurements, and optical post measurements are listed in Tab. 3 and show that the differences due to the individual measurement methods are lower than the differences between the experiments with different particle impact. Consequently, the influence due to the different particle concentrations is significant.

Tab. 3 SLPG-DLC liner wear values of RIC continuous total wear, RIC post measurements, and optical post measurements. RIC post measurements show the distribution of DLC wear in components after experiment. The main proportion deposited in the filter compared to the lubricant, the circuit, and the counter-body.

\begin{tabular}{|c|c|c|c|c|c|c|c|c|c|}
\hline \multirow{3}{*}{ 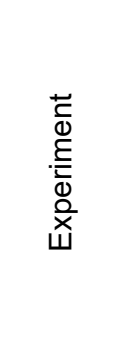 } & \multirow[b]{3}{*}{ 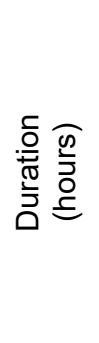 } & \multirow{3}{*}{ 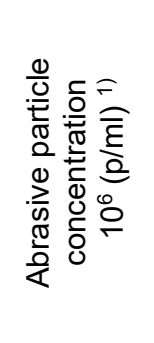 } & \multicolumn{7}{|c|}{ Wear volume $10^{6}\left(\mu \mathrm{m}^{3}\right)$} \\
\hline & & & \multirow[b]{2}{*}{ 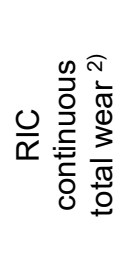 } & \multirow[b]{2}{*}{ 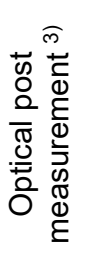 } & \multicolumn{5}{|c|}{ RIC wear in component - post measurement ${ }^{2)}$} \\
\hline & & & & & $\begin{array}{l}\bar{\pi} \\
\frac{\pi}{0}\end{array}$ & 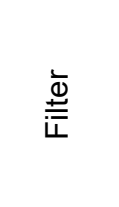 & $\begin{array}{l}\text { 들 } \\
\text { 은 } \\
\text { 윽 }\end{array}$ & 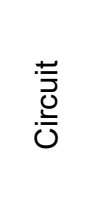 & 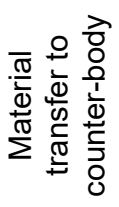 \\
\hline SLPG-A & 6 & 7 & 4.5 & 4.2 & 4.4 & 3.5 & 0.3 & 0.5 & 0.1 \\
\hline SLPG-B & 5 & 4 & 3.3 & 3.0 & 3.9 & 2.5 & 1.2 & 0 & 0.2 \\
\hline SLPG-C & 5 & 1 & 2.0 & 2.1 & 2.3 & 1.5 & 0.4 & 0.1 & 0.3 \\
\hline SLPG-D & 18 & $\begin{array}{l}\text { Variation } \\
<0.1 \text { to } 2\end{array}$ & 7.0 & 6.6 & 7.3 & 5.9 & 0.3 & 1.1 & 0 \\
\hline \multicolumn{5}{|c|}{ Percent-distribution in component of total wear (\%) } & 100 & $72 \pm 9$ & $15 \pm 13$ & $8 \pm 7$ & $6 \pm 6$ \\
\hline
\end{tabular}

\footnotetext{
1) The abrasive particle concentration is given in particles $/ \mathrm{ml}(\mathrm{p} / \mathrm{ml}) \pm 50 \%$.

2) Including substrate wear, uncertainty of DLC wear volume is $\pm 0.6 \times 10^{6} \mu \mathrm{m}^{3}$.

3) Uncertainty is $\pm 0.5 \times 10^{6} \mu \mathrm{m}^{3}$.
} 


\subsection{Abrasive particles and DLC wear}

Three lubricant samples were taken at different time steps of a loading condition. These lubricant samples include the initial particles plus DLC wear particles $<1 \mu \mathrm{m}$ minus the particles taken out by the $1 \mu \mathrm{m}$ filter. However, we did not recognize a correlation between the test duration and the evaluated abrasive particle concentration within each loading condition. Therefore, we averaged the three evaluated particle concentrations for each loading condition, which are listed in Tab. 3 .

Although our particle measurement here already gives a good insight into the subject, further studies are needed for more details.

Tests with ramps and tests with constant velocity from SLPG-DLC tests with abrasive particles were carried out. Pre-tests with low abrasive particle concentration $<10^{5}$ particles per milliliter showed that there is no significant influence on the wear when comparing exactly these ramp tests and exactly these constant velocity tests.

The results show that from experiment SLPG-A to $\mathrm{C}$, as the abrasive particle concentration decreases, the wear volume also decreases. The largest wear volume was found at experiment $D$, which had the longest duration. The progression of the wear indicates that the wear observed in this study is a continuous or slightly progressing process under $275 \mathrm{MPa}$ initial pressure, sliding conditions and abrasive particles.

Thus, DLC particles are continuously removed over time. If large areas broke out at once, it would be apparent to the continuous data in the form of a step in the wear curve.

Areas, where the DLC coating is rubbed off and the substrate is visible, are shown in the optical image of the SLPG-DLC liner sample, as dark blue scratches in sliding direction, Fig. 8a. These are as well observable in the Abbott-distribution of the wear depth between -2 and $-3 \mu \mathrm{m}$, Fig. $8 \mathrm{~b}$. The Abbottdistribution can be described by two individual peaks, which lead to the conclusion, that two different wear mechanisms lead to that surface structure. Firstly, mild abrasive wear due to abrasives is indicated by the worn areas where the DLC coating is still present. In these areas lines (scratches on DLC surface) are visible in sliding direction due to interaction of the particles and DLC coating.

Secondly, scratches with a wear depth in the range of the DLC coating are indicated as wear-off. For these areas delamination is the obvious wear mechanism.

As most of the RIC signal is measured in the filter and the filter has a mesh width of $1 \mu \mathrm{m}$, we may conclude that most of the DLC wear volume occurs as wear particles $>1 \mu \mathrm{m}$. Whether these are indicators of delamination or not, is not yet clear. Further studies need to be conducted on this aspect.

(a)

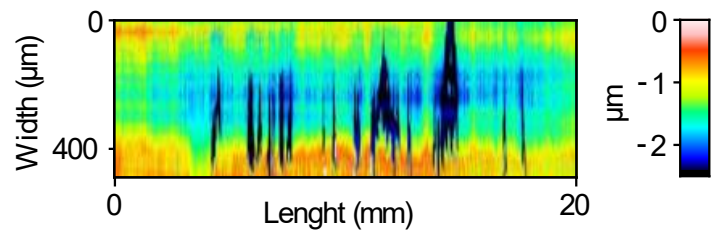

(b)

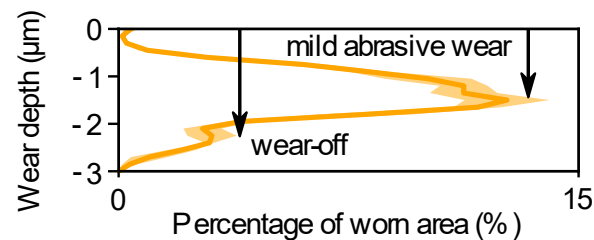

Fig. 8 Wear zone of the SLPG-B experiment: optical image of the wear track with vertical sliding direction (a) and the Abbott distribution within the wear zone (b).

In literature, a wear coefficient $\left(\mathrm{mm}^{3} / \mathrm{Nm}\right)$ is often given to compare results. The wear coefficient of the UMT oscillating experiments in this study is $5 \times 10^{-9} \mathrm{~mm}^{3} / \mathrm{Nm}$ and the wear coefficients from SLPG tests are in the range of 3 to $10 \times 10^{-9} \mathrm{~mm}^{3} / \mathrm{Nm}$, respectively. Michler et al. reported higher values for tribotests with rotating balls and cylinders while testing with abrasive particles [42]. Khadem et al. [43] and Muhyiddin et al. [44] reported that delamination was observed for similar wear rates but without abrasive particles. This proves that the loading conditions are sufficiently selected. Although the methods in this study provide a good insight into the subject.

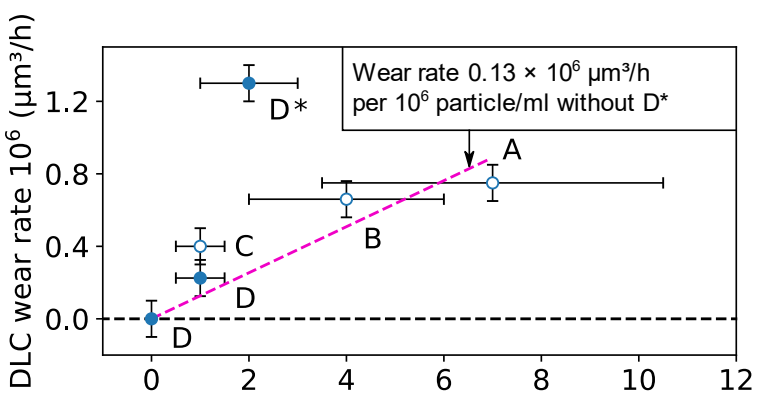

Abrasive particle concentration $10^{6}$ (particle $/ \mathrm{ml}$ )

Fig. 9: The wear rate shows a correlation with the abrasive particle concentration from SLPG-DLC liner experiments (A-B-C and D). $D^{*}$ was excluded due to it being an outlier. 
Nevertheless, the DLC wear behavior due to abrasive particles can be indicated in this study by the wear rate per abrasive particle concentration, Fig. 9.

Furthermore, comparing UMT (high initial pressure, no abrasive particles) and SLPG (low initial pressure with abrasive particles) experiments: DLC wear-off was not observed in the UMT tests, although the pressure was about ten times higher than in the SLPG tests. Consequently, abrasive particles can cause engine component to fail at low pressures in real applications.

\section{Conclusion}

The following main conclusions can be drawn from this study:

1) The RIC irradiation method has no significant influence on the tribological behaviour of DLC coatings. Therefore, DLC can be ineffective irradiated for RIC wear investigations.

2) DLC wear was determined, and a continuous wear progress was observed at the presence of abrasive particles. The experimental methods in this study are beneficial for wear investigations under different loading conditions and for differentiating DLC, for instance, doped-DLC coatings or DLC coatings with different sp2/sp3 ratios.

3) Wear-off from DLC due to abrasive particles and unidirectional sliding was observed to be a continuous process, where the DLC wear rate can be correlated with the abrasive particle concentration.

Summarizing, DLC performance is outstanding under oscillating and unidirectional sliding conditions even at high contact pressures. However, at the presence of hard abrasive particles (eventually from another tribo-contact) a significant increase of the wear rate occurs, which may become a critical parameter limiting the lifetime in different automotive applications.

\section{Acknowledgments}

This work was funded by the Austrian COMET Program (project K2 InTribology1, no. 872176). The work has been carried out within the TU Vienna (Austria) and the "Excellence Centre of Tribology" (AC2T research $\mathrm{GmbH}$ ). TEM investigations were carried out using the USTEM facilities at the TU Vienna, Austria.

\section{References}

[1] A. Erdemir and C. Donnet, "Tribology of diamond-like carbon films: Recent progress and future prospects," Journal of Physics D: Applied Physics, vol. 39, no. 18. Sep. 21, 2006. doi: 10.1088/0022-3727/39/18/R01.

[2] C. Donnet and A. Erdemir, Tribology of diamond-like carbon films: fundamentals and applications, 2008th ed. 2008.

[3] E. L. Dalibón, J. N. Pecina, M. N. Moscatelli, M. A. Ramírez Ramos, V. J. Trava-Airoldi, and S. P. Brühl, "Mechanical and Corrosion Behaviour of DLC and TiN Coatings Deposited on Martensitic Stainless Steel," Journal of Bio- and TriboCorrosion, vol. 5, no. 2, Jun. 2019, doi: 10.1007/s40735-019-0228-6.

[4] Y. Xiao, W. Shi, J. Luo, and Y. Liao, "The tribological performance of TiN, $\mathrm{WC} / \mathrm{C}$ and DLC coatings measured by the four-ball test," Ceramics International, vol. 40, no. 5, pp. 6919 6925, Jun. 2014, doi: 10.1016/j.ceramint.2013.12.015.

[5] A. Tschiptschin, S. K. Kolawole, F. O. Kolawole, A. P. Tschiptschin, S. K. Kolawole, and M. Antonio, "Failure of diamond-like carbon (DLC) coatings in automobile engines - A Review," 2019. [Online]. Available: https://www.researchgate.net/publication/33409 4215

[6] A. Tyagi, R. S. Walia, Q. Murtaza, S. M. Pandey, P. K. Tyagi, and B. Bajaj, "A critical review of diamond like carbon coating for wear resistance applications," International Journal of Refractory Metals and Hard Materials, vol. 78. Elsevier Ltd, pp. 107-122, Jan. 01, 2019. doi: 10.1016/j.ijrmhm.2018.09.006.

[7] K. Holmberg and A. Erdemir, "The impact of tribology on energy use and $\mathrm{CO} 2$ emission globally and in combustion engine and electric cars," Tribology International, vol. 135, pp. 389396, Jul. 2019, doi: 10.1016/j.triboint.2019.03.024.

[8] S. D. A. Lawes, M. E. Fitzpatrick, and S. v Hainsworth, "Evaluation of the tribological properties of DLC for engine applications," Journal of Physics D: Applied Physics, vol. 40, no. 18 , Sep. 2007, doi: 10.1088/0022$3727 / 40 / 18 / \mathrm{S} 03$.

[9] R. Hauert, K. Thorwarth, and G. Thorwarth, "An overview on diamond-like carbon coatings in medical applications," Surface and Coatings Technology, vol. 233, pp. 119-130, Oct. 2013, doi: 10.1016/j.surfcoat.2013.04.015.

[10] X. Fan, Q. J. Xue, and L. Wang, "Carbon-based solid-liquid lubricating coatings for space applications-A review," Friction, vol. 3, no. 3. Tsinghua University Press, pp. 191-207, Sep. 01, 2015. doi: 10.1007/s40544-015-0079-1.

[11] V. Renman, "Tribological testing of DLC coatings for automotive applications," 2012. [Online]. Available: 
[12] M. Kano, "DLC Coating Technology Applied to Sliding Parts of Automotive Engine," 2006.

[13] M. Kano, "Diamond-like carbon coating applied to automotive engine components," Tribology Online, vol. 9, no. 3. Japanese Society of Tribologists, pp. 135-142, 2014. doi: 10.2474/trol.9.135.

[14] T. Haque, D. Ertas, A. Ozekcin, H. W. Jin, and R. Srinivasan, "The role of abrasive particle size on the wear of diamond-like carbon coatings," Wear, vol. 302, no. 1-2, pp. 882-889, Apr. 2013, doi: 10.1016/j.wear.2013.01.080.

[15] P. Brisset et al., "Radiotracer Technologies for Wear, Erosion and Corrosion Measurement," 2020.

[16] T. Wopelka et al., "Wear of different material pairings for the cylinder liner - piston ring contact," Industrial Lubrication and Tribology, vol. 70, no. 4, pp. 687-699, 2018, doi: 10.1108/ILT-07-2017-0218.

[17] E. Corniani, M. Jech, T. Wopelka, F. Ditrói, F. Franek, and A. Pauschitz, "High-resolution wear analysis of a ball-on-disc contact using lowactivity radioactive isotopes," Proceedings of the Institution of Mechanical Engineers, Part C: Journal of Mechanical Engineering Science, vol. 226, no. 2, pp. 319-326, Feb. 2012, doi: $10.1177 / 0954406211424865$.

[18] M. Jech, "Wear Measurement at Nanoscopic Scale by means of Radioactive Isotopes," 2012.

[19] F. Ditrói et al., "Sub-micron wear measurement using activities under the free handling limit," Journal of Radioanalytical and Nuclear Chemistry, vol. 292, no. 3, pp. 1147-1152, 2012, doi: 10.1007/s10967-012-1625-1.

[20] M. L. Miranda-Medina, S. Spiller, A. Vernes, and M. Jech, "Spectroscopic ellipsometry and X-ray photoelectron comparative studies of tribofilms formed on cast iron surfaces," Tribology International, vol. 113, pp. 101-110, 2017, doi: 10.1016/j.triboint.2016.12.021.

[21] P. Peterko, C. Habersohn, C. Lechner, H. Kaminski, M. Jech, and F. Bleicher, "Mechanisch-dynamische Prüfung tribotechnischer Funktionsschichten Untersuchung des Einflusses des Schlagverdichtens auf die tribologischen Eigenschaften von Metalloberflächen," 2011.

[22] P. Berlet, J. Daul, P. Erhard, P. Fehsenfeld, and K. Pöhlmann, "Dünne Schichten und Oberflächentechnologien - Eine neue Methode zur tribologischen Beurteilung von DLCBeschichtungen," 2008.

[23] J. Faller and M. Scherge, "The Identification of an Adequate Stressing Level to Find the Proper Running-In Conditions of a Lubricated DLCMetal-System," Lubricants, vol. 8, no. 9, p. 88, Aug. 2020, doi: 10.3390/lubricants8090088.

[24] H. Tani, R. Naito, R. Lu, S. Koganezawa, and N. Tagawa, "Low Friction of Diamond-Like Carbon Film Due to Liquid Hydrocarbon Generated by Laser Heating in a Nitrogen Gas Environment," Tribology Letters, vol. 68, no. 3, Sep. 2020, doi: 10.1007/s11249-020-01333-6.

[25] H. Fan et al., "The influence of helium ion irradiation on amorphous hydrocarbon films," Journal of Nuclear Materials, vol. 435, no. 1-3, pp. 214-221, 2013, doi: 10.1016/j.jnucmat.2012.12.048.

[26] V. D. Vankar and N. Dilawar, "Ion irradiation effects in carbon thin films*," 1998.

[27] Y. Wu et al., "Influences of Space Irradiations on the Structure and Properties of MoS2/DLC Lubricant Film," Tribology Letters, vol. 64, no. 2, Nov. 2016, doi: 10.1007/s11249-016-0759-7.

[28] N. Zhang, L. Lin, B. Liu, G. Wu, W. Xu, and T. Peng, "Tribological properties improvement of H-DLC films through reconstruction of microstructure and surface morphology by lowenergy helium ion irradiation," Diamond and Related Materials, vol. 109, Nov. 2020, doi: 10.1016/j.diamond.2020.108080.

[29] B. Lesiak et al., "C sp 2 /sp 3 hybridisations in carbon nanomaterials - XPS and (X)AES study," Applied Surface Science, vol. 452, pp. 223-231, Sep. 2018, doi: 10.1016/j.apsusc.2018.04.269.

[30] F. Ditrói, S. Takh, F. Th-Khyi, and I. Mahunka, "Study of the nat-C $(3 \mathrm{He}, 2 \alpha) \quad 7 \mathrm{Be}$ and $9 \mathrm{Be}(3 \mathrm{He}, \alpha \mathrm{n}) 7 \mathrm{Be}$ nuclear reactions and their applications for wear measurements," 1995.

[31] “CL2013-Council-Directive-irradiation,” 2013.

[32] C. Haiden, "Dissertation Optical Micro-and Nanoparticle Characterization in Microfluidics," 2016.

[33] T. F. Zhang et al., "Tribological behavior of diamond like carbon film sliding against CoCrMo or $\mathrm{Al} 2 \mathrm{O} 3$ in air and water environment," Tribology International, vol. 95, pp. 456-461, Mar. 2016, doi: 10.1016/j.triboint.2015.08.050.

[34] D. Tischler, Z. Budinská, P. Vlčák, and I. Štěpánek, "NANOINDENTATION TEST FOR DLC COATING ANALYSIS," Nanoindentation test for DLC coating analysis Materials Engineering-Materiálové, vol. 18, pp. 105-109, 2011.

[35] P. K. Chu and L. Li, "Characterization of amorphous and nanocrystalline carbon films," Materials Chemistry and Physics, vol. 96, no. 23, pp. 253-277, Apr. 2006, doi: 10.1016/j.matchemphys.2005.07.048.

[36] V. Serin, "eels database graphite," https://eelsdb.eu/spectra/graphite/, 2005.

[37] K. Y. Li and S. M. Hsu, "A quantitative wear measurement method on production engine parts: Effect of DLC thin films on wear," Wear, vol. 426-427, pp. 462-470, Apr. 2019, doi: 10.1016/j.wear.2019.01.054.

[38] G. Genta and G. Maculotti, "Uncertainty evaluation of small wear measurements on complex technological surfaces by machine vision-aided topographical methods," CIRP Annals, 2021, doi: 10.1016/j.cirp.2021.04.057.

[39] G. Smith, "Refraction and visual acuity measurements: What are their measurement uncertainties?," Clinical and Experimental 
Optometry, vol. 89, no. 2, pp. 66-72, Mar. 2006, doi: 10.1111/j.1444-0938.2006.00022.x.

[40] JCGM, "Evaluation of measurement data-Guide to the expression of uncertainty in measurement Évaluation des données de mesure-Guide pour l'expression de l'incertitude de mesure," 2008. [Online]. Available: www.bipm.org

[41] F. Mullan, D. Bartlett, and R. S. Austin, "Measurement uncertainty associated with chromatic confocal profilometry for 3D surface texture characterization of natural human enamel," Dental Materials, vol. 33, no. 6, pp. e273-e281, Jun. 2017, doi: 10.1016/j.dental.2017.04.004.

[42] T. Michler and C. Siebert, "Abrasive wear testing of DLC coatings deposited on plane and cylindrical parts," 2003.

[43] M. Khadem, T. L. Park, O. v. Penkov, and D. E. Kim, "Highly transparent micro-patterned protective coatings on polyethylene terephthalate for flexible solar cell applications," Solar Energy, vol. 171, pp. 629-637, Sep. 2018, doi: 10.1016/j.solener.2018.07.023.

[44] M. Muhyiddin et al., "Effect of Pillar and Mesh Structure of Tetrahedral Amorphous Carbon (taC) Coatings on the Wear Properties and Fracture Toughness of the Coating," 2019. [Online]. Available: http://www.tribology.jp/trol/

\section{Statements \& Declarations}

Funding see 6 . Acknowledgments.

The authors have no relevant financial or nonfinancial interests to disclose.

All authors contributed to the study conception and design. Material preparation, data collection and analysis were performed by Manuel Zellhofer. The first draft of the manuscript was written by Manuel Zellhofer and Martin Jech, and all authors commented on previous versions of the manuscript. All authors read and approved the final manuscript. 